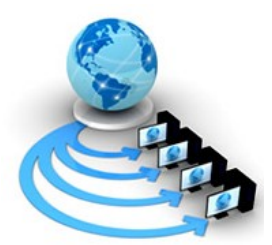

Volume 10, No. 2, March-April 2019

International Journal of Advanced Research in Computer Science

RESEARCH PAPER

\title{
DENTAL ADVISORIES AND SMS NOTIFICATION SYSTEM UTILIZING PREDICTIVE ANALYTICS
}

\author{
Ma.Grace P. Miranda \\ College of Computer Studies \\ Trimex Colleges, Biñan, Laguna, Philippines \\ Mark Joseph Q. Rey \\ College of Computer Studies \\ Trimex Colleges, Biñan, Laguna, Philippines
}

\author{
John Thomas M. Bansil \\ College of Computer Studies \\ Trimex Colleges, Biñan, Laguna, Philippines
}

\author{
Mary Joy T. Beler \\ College of Computer Studies \\ Trimex Colleges, Biñan, Laguna, Philippines
}

\author{
Louie F. Agustin \\ College of Computer Studies \\ Trimex Colleges, Biñan, Laguna, Philippines
}

\begin{abstract}
The development of Information Technology has been advisable for all establishments and enterprise organizations as nicely as the clinical field. With the use of superior technology, transactions, processing, and operations grew to be faster, correct and useful. This study focuses on the efficiency of advisories and SMS notification, especially to the Dental Industry. The system goals to ease the manual tracking of patients, reducing the time of waiting for patients and increasing the number of patients served in unique Dental Clinics. The system is ubiquitous and efficient as it is online and gives a paperless application that can without problems discover a patient list and preceding transaction. The device is successful of rapidly notifying the sufferers regarding the popularity of their session the usage of SMS Notification and has decision support function that can provide a useful resource in terms of deciding on fabulous sales and advertising strategies for the company. The system also makes use of Predictive Analytics to furnish choice help in terms of Sales strategies for the business.
\end{abstract}

Keywords: SMS Notification, Predictive Analytics, Dental Appointment, Scheduling, Automated Advisories

\section{INTRODUCTION}

Today's generation of technology has been interchanging every now and then. As time goes by, computers are being utilized steadily greater in minimizing the amount of time wanted to accomplish a task. In this generation, these machines can now be regarded as requirements and as for the Dental Clinic Industry; it has taken steps to innovation when it comes to monitoring affected person archives and notifying them for appointments and announcements.

Clinics have been the use of general workplace purposes for retaining data but these apps are susceptible to loss of information integrity and redundancy. Also, clinics have been using cell telephones for quite a whilst to inform their patients for their subsequent visits however, there are nonetheless lapses when you consider that most of the time the notification method is made by way of the health center receptionist, in my view sending a text message to the clients. Through this method, the procedure is susceptible to human-error that might also reason unorganized time table of physician appointments. As the proponents probed on the dilemmas of the industry, they have come up with a device that will be in a position to keep patients file in a secured database on the cloud with automatic SMS notification for the patients' upcoming dental appointments and makes use of predictive analytics for managerial selection making.

Elaborating greater on the functions and points of the project, the Dental Advisories and SMS Notification System Utilizing Predictive Analytics is a web-application that is comprised of three foremost modules: Administrator, SMS Notification and Predictive Analytics.

The Administrator module permits the user to add affected person information, dental issues if there are any, and the provider rendered during his or her go to with the visual representation of the patient's dental structure. Moreover, the SMS Notification module automatically sends a affected person their next doctor's appointment according to the service the he or she has availed and if there are critical medicinal drugs to intake. Lastly, the Predictive Analytics module depicts the summary of all offerings availed by way of the customers of the clinic thru a bar graph; it functions as a selection assist module for the administration to resource the executives in decision making when it comes to the sales strategies they can impose to generate extra income.

\section{LITERATURE SURVEY}

According to the Authors, the study is developed to provide automated advisories ${ }^{[1]}$ for the patients of a dental clinic. 
As mentioned, the system shall send automated advisories to the patients, and the process shall be done using SMS notification. ${ }^{[2]}$

Furthermore, the Authors also added a decision support module thru the use of predictive analytics ${ }^{[3]}$.

\subsection{DESIGN OF THE STUDY}

The system is designed primarily for the administrator, being able to manage all the functions of the system including SMS notification and the predictive analytics module. However, the system cannot work offline, meaning that the user has to login to the system thru an active internet connection.

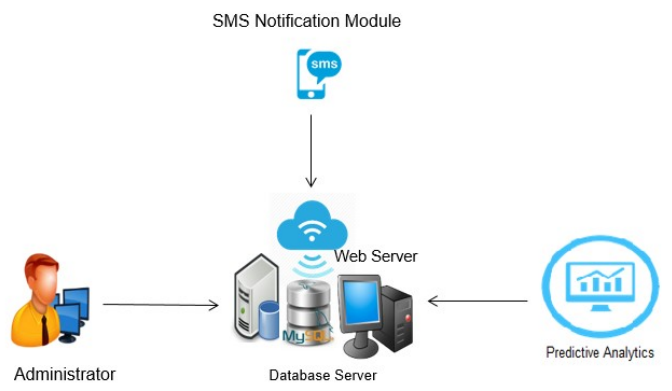

Figure 1. System Architecture

\subsection{USE CASE DIAGRAM}

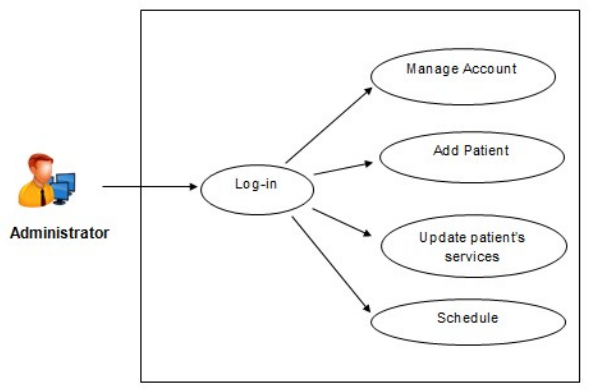

Figure 2. Use Case Diagram of Administrator Module

The figure above shows the use case diagram for administrator module, the administrator has to login in order to validate the username and password for security purposes. If the username and password are correct, the admin can now manage account, add patient, check the schedule of the patients and update its services.

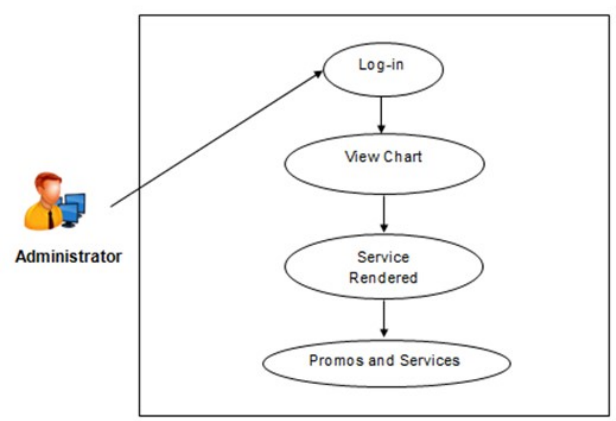

Figure 3. Use Case Diagram of Predictive Analytics Module
This figure shows the predictive analytics module, the administrator will log in. After that, the admin can view chart of service rendered and promos and services.

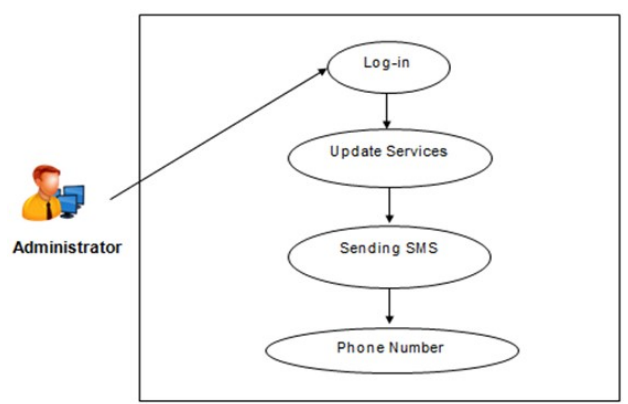

Figure 4. Use Case Diagram of SMS Notification Module

The figure 4 shows the SMS notification module. First the administrator has to login and update the services. After updating the services availed by the patient, it will automatically send the patient's next dental appointment

\section{RESULTS AND DISCUSSION}

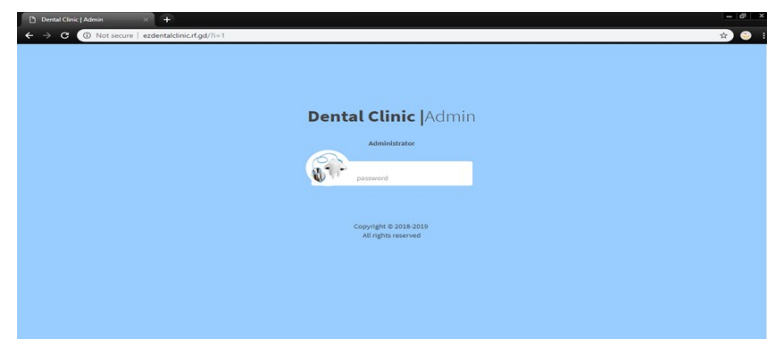

Figure 5. Administrator Login Page

The figure above shows the homepage of Dental Advisories and SMS Notification utilizing Predictive Analytics. The admin need to $\log$ in to add, update, and edit the patients' information.

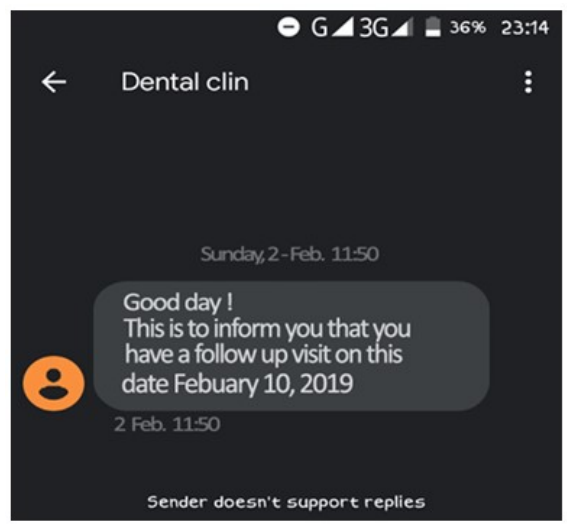

Figure 6. SMS Notification

The figure shows a system generated SMS notification sent to the patient, reminding his or her next dental appointment. 


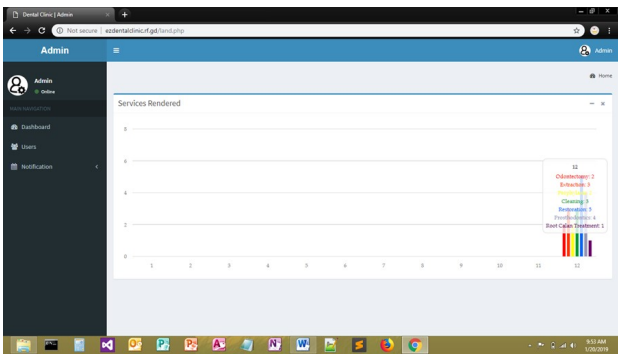

Figure 7. Predictive Analytics

The page shows a graph containing all the services being availed by the clients of the clinic. The management now can interpret the clinic's sales and marketing status. From there, they can come up with the strategies to improve their services or broadcast promotions to increase the income of the company.

\section{CONCLUSION}

The Dental Advisories and SMS Notification System Utilizing Predictive Analytics can be of excellent help to dental clinics especially to those who are having difficulties with speaking to their patients when it comes to the dental schedules.

The gadget is ubiquitous and environment-friendly as it is online and offers a paperless utility that can quickly locate patient listing and previous transaction.

This study recommended for each of the clinic's consumers and management. The gadget is successful of unexpectedly notifying the patients concerning the fame of their session through the ability of SMS Notification and has choice aid characteristic that can resource in terms of deciding on suitable income and advertising strategies for the company.

\subsection{RECOMMENDATIONS}

The researchers of the study further recommended the following:

1. Make the system available for other platforms and mobile devices.

2. The researchers are looking forward on adding an offline version of the system.

3. Add more features that will help the administrator and clients.

\section{REFERENCES}

[1] Mobile based advisory system and a method thereof Google Patents. (2015, January 20). Retrieved from https://patents.google.com/patent/US8938218B2/en

[2] Starr, K., McPherson, G., Forrest, M., \& Cotton, S. (2015). SMS text pre-notification and delivery of reminder e-mails to increase response rates to postal questionnaires: a factorial design, randomised, controlled trial. Trials, 16(S2). doi:10.1186/1745-621516-s2-p88

[3] Schoenherr, T., \& Speier-Pero, C. (2015). Data Science, Predictive Analytics, and Big Data in Supply Chain Management: Current State and Future Potential. Journal of Business Logistics, 36(1), 120-132. doi: $10.1111 /$ jbl.12082

[4] Definition of Ubiquitous. (n.d.). Retrieved from https://www.merriamwebster.com/dictionary/ubiquitous 